\title{
The Motivation Factors of Sales Personnel in Financial Institutions
}

\author{
Sanja Bijakšić, Brano Markić \\ University of Mostar, Mostar, Bosnia and Herzegowina \\ Marko Šantić \\ University Clinical Hospital, Mostar, Bosnia and Herzegowina
}

\begin{abstract}
The motivation is an employee's internal relationship in the form of behaviour directed towards a specific goal and is manifested as an important factor for overall organisation performance. The goal of any business is to motivate employees to perform work with the maximum results. The work motivation is complex and dynamic feature of human resources and influences to motivation are very broad and diverse. The material forms of motivation are different compensation that employees receive for their work in the company. They appear in the financial and non-financial forms (paid or in the form of various services). The goal of this research is to identify the main factors of human resources motivation in financial institutions (banks). The questionnaire will be used as a research instrument and consists of two parts. The first part of the questionnaire will focus on socio-demographic characteristics and the second part concentrates on the motivation variables of material and immaterial character. Applying adequate knowledge discovery research methods will be identified as the main motivation components of selling persons in financial institutions.
\end{abstract}

Keywords: human resources management, knowledge discovery methods, motivation

\section{Introduction}

Motivation is, in most general sense, manifested as any influence that causes, directs, and reflects target behaviour of people (Buble, 2006, p. 336). It is realised by inclusion of whole chain of reactions from senses of needs to satisfaction. Different factors influence motivation. The term motivation comes from Latin word motus meaning movement, move (Anić, Klaić, \& Domović, 1999, p. 924) and with which it can be concluded that there is stimulating reason, stimulus for some action. Batijarević-Šiber (1999, p. 557) has defined motivation as a "common term for all internal factors that consolidate intellectual and physical energy, indicate and organise individual activities, direct behaviour and determines its direction, intensity, and duration".

As an activity motivation is related to management, guidance, and business management that lead to employees' satisfaction in both private and business aspects. Motivation cannot be directly "seen" or measured. Only indirect conclusion can be made about it, based on certain person's behaviour. It is very hard to conclude

Sanja Bijakšić, Prof. dr. sc., Marketing Department, Faculty of Economics, University of Mostar.

Brano Markić, Prof. dr. sc., Business Informatics Department, Faculty of Economics, University of Mostar.

Marko Šantić, MSc., Accounting Department, University Clinical Hospital.

Correspondence concerning this article should be addressed to Sanja Bijakšić, Prof.dr.sc.,Matice Hrvatske bb, 88000 Mostar, Bosnia and Herzegowina. E-mail: sanja.bijaksic@sve-mo.ba. 
precisely which motive stands behind certain behaviour; the same motives with different people can be satisfied by different actions.

Numerous factors influence motivation, out of them Porter and Miles especially emphasise the following three groups (Buble, 2006, p. 336):

- Individual characteristics - present those needs, values, attitudes, and interests that individuals possess. They differ from person to person;

- Job characteristics - present certain attributes of a job such as complexity, autonomy, requirements, etc.;

- Organisational characteristics - present rules and procedures of personal policy, management practices and award system that contributes to company's efficiency.

It is directed, as its name says, towards working motivation. Motivation is understood as a certain structure of attitudes and values that refer to primarily working and then general orientation of people. The sense of that theory is that it emphasises human need for achievement, which means aspiration for success. Aspiration for success is a result of two forces: The first is desire for success and the second is desire to avoid failure.

Therefore motivation is also caused by individual estimation of probability of achieving success or failure. Which one will turn the scale primarily to depend on severity of the task that should be accomplished. If the task is harder there is higher probability of a failure, but there is higher satisfaction of success and vice versa, easier task has higher probability of realisation but satisfaction of that success is lower. McClelland has added two new variables: power and affiliation.

Need for power is manifested in desire and tendency for influence and control of other's behaviour and it is a motive to overtake higher management positions in a company that requires individuals who would direct the work of others.

Affiliative need expresses an aspiration for belonging to and closeness with other people and individuals with such needs aspire to the tasks that are characterised by social interaction.

The aim of research is motivation of selling persons in financial institution with special emphasis on motivation of sales personnel in banking sector. The following questions are to be answered with this paper:

- Questions related to material factors of employees' motivation in sales department of the banks.

- Questions related to importance of material factors of motivation in banking sector.

- Questions related to non-material factors of employees' motivation in sales department of the banks.

- Questions related to importance of certain non-material factors of motivation in banking sector.

- Identify cause-and-effect relationship between general motivation and satisfaction of sales personnel in the banks.

\section{Discovering Knowledge in Data}

Research of influence of sales personnel motivation in financial institutions is based on data that "hide" knowledge and answers on the set hypotheses. Variables of material and non-material motivation of sales personnel in financial institutions can be reduced on lower number of principal components without losing information. This is the main research hypothesis. In research sense such hypothesis responds a requirement of knowledge extraction from data collected by a questionnaire.

Discovering knowledge from data is a process that is completely defined and in accordance with, in methodological view, phases of scientific research process. Research dynamics was implemented over the data in accordance with the set research hypotheses. The data can be structured as dataset or unstructured as a text. 
Text mining endeavours to detect regularities and hidden relations between terms in a text. Relations between the words detect in concise shape attitudes and opinions contained in a text. Such data do not have predetermined appearance and therefore are called unformatted data. Knowledge derivation from a text is not linear process but it can be theoretically showed as a row of sequenced steps: data approach, pre-processing, application of data mining algorithm, and presentation of the results (visualisation). Text mining is a complex task that has to be shared in parts since it is the only reasonable and possible procedure of complex tasks' analysis (Bijakšić, Markić, \& Bevanda, 2013, p. 414).

Data can be structured in a form of operational databases. Those are mostly big amounts of data that contain detailed data about business processes and are not adapted to business analyses. Therefore new bases are created from such data and they are used for analytical purposes. Such bases are called data warehouses, and process of their construction and packing is known as Extraction-Transformation-Loading (E-T-L) process. Data warehouses can later easily transform in a form of dataset over which data mining algorithms can be applied. Whole process of knowledge discovering is illustrated at the following Figure 1 (Markić, 2011).

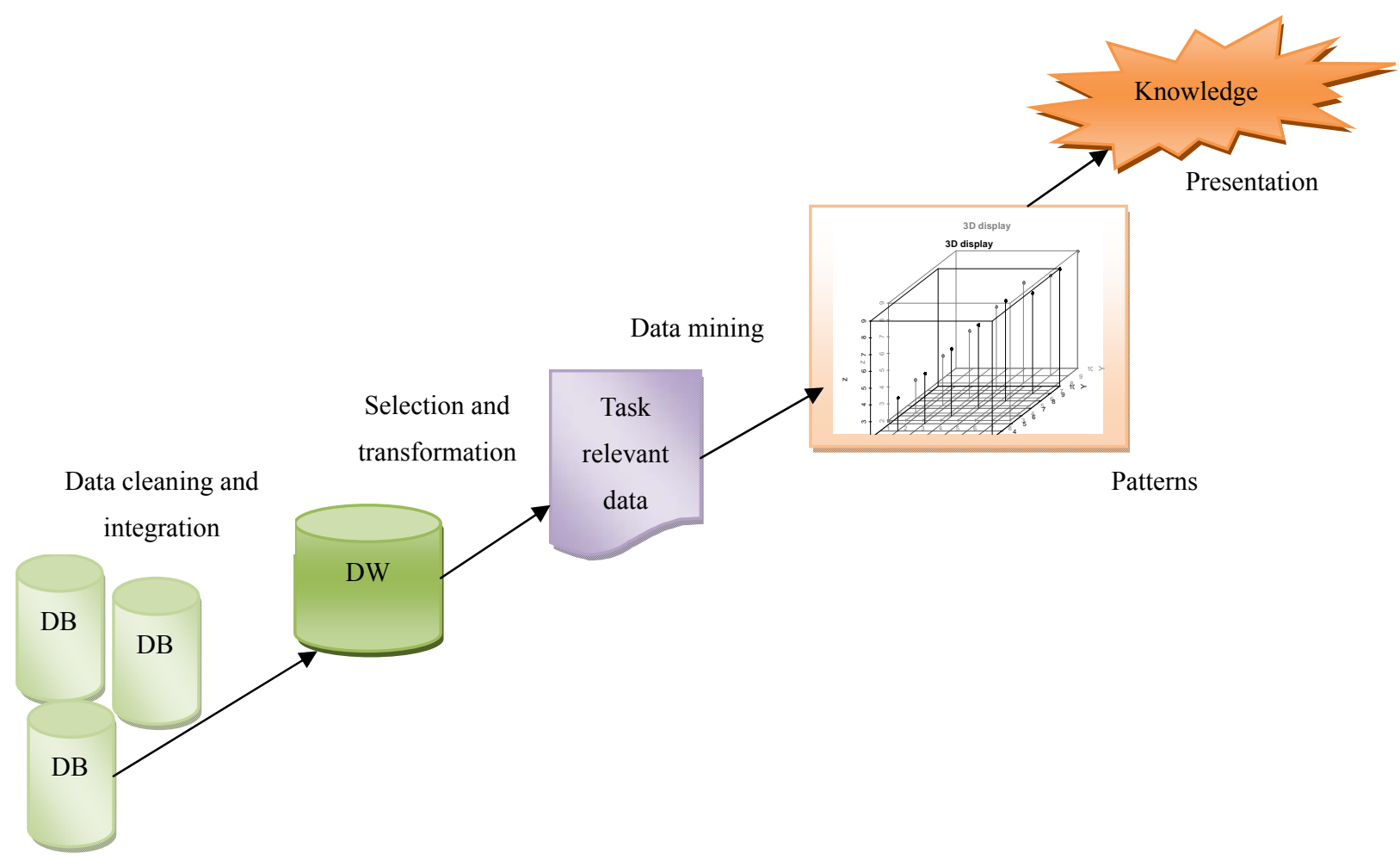

Figure 1. Knowledge discovery process.

Data in form of dataset were used in this paper. Those data are formed based on a questionnaire as an instrument of data collection. The result of a whole process is knowledge and it is the research hypothesis. Acceptance or rejection of the hypothesis is knowledge extracted from questionnaire data. Data mining is principal component analysis.

\section{Research Method}

\section{Principal Component Analysis}

Principal component analysis (PCA) is broadly used method (data mining algorithm) in socio-economic 
research. It is especially interesting for quality marketing research. It uses solutions of linear algebra of extracting information (components) of dataset. In mathematical way principal component analysis finds new coordination system with less coordinating axis containing as more as possible variability in data (which shows data with as lower as possible loss of information). Such procedure is also called reduction of data dimensionality.

\section{Definition of Principal Components}

If it is assumed that $X^{T}=\left[X_{1}, X_{2}, X_{3}, \ldots, X p\right]$ is accidental vector of dimensionality $p$ and if co-variance matrix $\Sigma$ with characteristic values (eigenvalues) is: $\lambda_{1} \geq \lambda_{2} \geq \ldots \geq \lambda_{p} \geq 0$.

If they are as follows:

$$
\begin{gathered}
Y_{1}=a_{1}^{T} X=a_{11} X_{1}+a_{12} X_{2}+\cdots+a_{1 p} X_{p} \\
Y_{2}=a_{2}^{T} X=a_{21} X_{1}+a_{22} X_{2}+\cdots+a_{2 p} X_{p} \\
\vdots \\
Y_{p}=a_{p}^{T} X=a_{p 1} X_{1}+a_{p 2} X_{2}+\cdots+a_{p p} X_{p}
\end{gathered}
$$

Linear elements' combinations of accidental vector $X$, while $a_{11}, a_{12}, a_{13}, \ldots, a_{1 p}$ are coefficients of linear combination.

If $\Sigma$ co-variance matrix is:

$$
\Sigma=\left(\begin{array}{cccccc}
\sigma_{11} & \sigma_{12} & \cdots & \sigma_{1 i} & \cdots & \sigma_{1 p} \\
\sigma_{21} & \sigma_{22} & & \sigma_{2 i} & & \sigma_{2 p} \\
\vdots & \vdots & & \vdots & & \vdots \\
\sigma_{j 1} & \sigma_{j 2} & \cdots & \sigma_{j i} & \cdots & \sigma_{j p} \\
\vdots & \vdots & & \vdots & & \vdots \\
\sigma_{p 1} & \sigma_{p 2} & \cdots & \sigma_{p i} & \cdots & \sigma_{p p}
\end{array}\right)
$$

Sum variance of two variables is equal to:

$$
\operatorname{Var}\left(a_{1} X+a_{2} Y\right)=a_{1}^{2} \operatorname{Var}(X)+a_{2}^{2} \operatorname{Var}(Y)+2 a_{1} a_{2} \operatorname{Cov}(X, Y)
$$

or in matrix form:

$$
\begin{aligned}
& \operatorname{Var}\left(a_{1} X+a_{2} Y\right)=\underbrace{\left[\begin{array}{ll}
a_{1} & a_{2}
\end{array}\right]}_{=a^{T}} \underbrace{\left[\begin{array}{cc}
\operatorname{Var}(X) & \operatorname{Cov}(X, Y) \\
\operatorname{Cov}(X, Y) & \operatorname{Var}(Y)
\end{array}\right]}_{=\Sigma}] \underbrace{\left\langle\left[\begin{array}{l}
a_{1} \\
a_{2}
\end{array}\right]\right\rangle}_{=a} \\
& =a^{T} \Sigma a
\end{aligned}
$$

Therefore $\operatorname{Var}\left(Y_{i}\right)=a_{i}^{T} \Sigma a_{i} a \operatorname{Cov}\left(Y_{i}, Y_{k}\right)=a_{i}^{T} \Sigma a_{k}$.

Principal components are those linear combinations $Y_{1}, Y_{2}, Y_{3}, \ldots, Y_{\mathrm{p}}$ with the highest variances. Variance $\operatorname{Var}\left(Y_{1}\right)=a_{1}^{T} \Sigma a_{1}$ can be, if desired, increased by multiplication of vector $a_{i}$ with some scalar. Therefore new limitation is introduced in which a vector of unit length is $a_{1}^{T} a_{1}=1$. Such problem of maximum is solved using Lagrange multiplier. It is necessary to maximize a function:

$$
\max \left(\operatorname{Var}\left(Y_{1}\right)\right)=a_{1}^{T} \Sigma a_{1} \text { with constrain } a_{1}^{T} a_{1}=1 .
$$


Lagrange function is formed from a function and a limitation $a_{1}^{T} \Sigma a_{1}-\lambda\left(a_{1}^{T} a_{1}-1\right)$ where $\lambda$ is Lagrange multiplier. The function is maximized by equalization of the first derivation by $a_{1}$ with zero:

$$
\begin{gathered}
\frac{\partial}{a_{1}}\left(a_{1}^{T} \Sigma a_{1}-\lambda\left(a_{1}^{T} a_{1}-1\right)\right)=0 \\
\Sigma a_{1}-\lambda a_{1}=0 \\
(\Sigma-\lambda I) a_{1}=0
\end{gathered}
$$

where $I$ is unit matrix of $p \times p$ dimensions. Determinant $|\Sigma-\lambda I|$ must be equal to zero to obtain non-trivial solution. Therefore $\lambda$ is one of characteristic roots of co-variance matrix $\Sigma$. Based on condition $(\Sigma-\lambda I) a_{1}=0$ $a_{1}$ is characteristic vector that responds to characteristic solution $\lambda_{1}$. Standardising characteristic vector $\left(a_{1}^{T} a_{1}=1\right)$ vector $a_{1}$ is obtained.

If the task is to determine the second component then the procedure is repeated.

If it is $Y_{2}=a_{2}^{T} X=a_{21} X_{1}+a_{22} X_{2}+\cdots+a_{2 p} X_{p}$ which components $a_{21}, a_{22}, \ldots, a_{2 p}$ should be determined under condition that $a_{2}^{T} a_{2}=1$.

Firstly, co-variance is determined:

$$
\operatorname{Cov}\left(\mathrm{Y}_{2}, \mathrm{Y}_{1}\right)=\operatorname{Cov}\left(\mathrm{a}_{2}^{\mathrm{T}} \mathrm{X}, \mathrm{a}_{1}^{\mathrm{T}} \mathrm{X}=\mathrm{a}_{2}^{\mathrm{T}} \sum \mathrm{a}_{1}=\mathrm{a}_{1}^{\mathrm{T}} \sum \mathrm{a}_{2}=\mathrm{a}_{2}^{\mathrm{T}} \mathrm{a}_{1} \lambda_{1}=\mathrm{a}_{1}^{\mathrm{T}} \mathrm{a}_{2} \lambda_{1}\right.
$$

Since $\sum a_{1}-\lambda a_{1}=0$, and $a_{2}^{T} \mathrm{a}_{1} \lambda_{1}=0$ only for $a_{2}^{T} \mathrm{a}_{1}=0$ it is necessary to create Lagrange function for two constrains and two multipliers $\lambda$ and $\varphi$ :

$$
a_{2}^{T} \Sigma a_{2}-\lambda\left(a_{2}^{T} a_{2}-1\right)-\varphi a_{2}^{T} a_{1}
$$

By differentiation of $a_{2}$ and equalising it with zero the result is as follows:

$$
\Sigma a_{2}-\lambda a_{2}-\varphi a_{1}=0
$$

If obtained expression from the left side is multiplied by $a_{1}^{T}$ the result is as follows:

$$
a_{1}^{T} \Sigma a_{2}-\lambda a_{1}^{T} a_{2}-\varphi a_{1}^{T} a_{1}=0
$$

Since two first members are equal with zero an $a_{1}^{T} a_{1}=1$ it follows that $\varphi=0$. Therefore $\Sigma a_{2}-\lambda a_{2}=0$ or $(\Sigma-\lambda I) a_{2}=0 . T$ means that $\lambda$ is characteristic value (eigenvalue) of co-variance matrix $\Sigma$ while $a_{2}$ is 
characteristic vector (eigenvector). The researchers have chosen as higher as possible characteristic value $\lambda$ as well as for the first component since $\lambda=a_{2}^{T} \sum a_{2}$. The second characteristic value is marked with $\lambda_{2}$.

Following the same logics all principal components can be calculated. Their number is equal to number of characteristic values of co-variance matrix. If all characteristic values of co-variance matrix are different then their number is equal to number $p$ (there are $p$ principal components). Vectors of principal components coefficient are $a_{1}, a_{2}, a_{3}, \ldots, a_{p}$ which are characteristic vectors of co-variance matrix $\Sigma$. Expected value of the principal component is $\mathrm{E}\left(Y_{j}\right)=0$ a variance $\operatorname{Var}\left(Y_{j}\right)=\lambda_{j}$. All principal components are vertical so their angle cosinus (correlation coefficient) is equal to zero and thus co-variance of every pair of principal components is also equal to zero. In programming language $R$ there are corresponding functions that calculate co-variance matrixes, characteristic values, and characteristic co-variance matrix vectors. Those functions will be showed in experimental results.

\section{Research Results}

Coefficient of questionnaire's internal consistency as a research instrument is based on reliability coefficient known as Cronbach's coefficient. It is calculated by the application of the following formula:

$$
\alpha=\frac{n}{n-1}\left(1-\frac{\sum_{i=1}^{n} \sigma_{Y i}^{2}}{\sigma_{X}^{2}}\right)
$$

where:

$n$ : Number of questions in questionnaire;

$\sigma_{Y i}^{2}$ : Variance of response on a question $\mathrm{Y}_{\mathrm{i}}$, and

$\sigma_{X}^{2}$ : sum variance on responses to all questions in a questionnaire.

If sum variance on responses to all questions in a questionnaire is higher, than Cronbach alpha is higher, and a questionnaire is more consistent. With the application of the following orders of $R$ language the coefficient of questionnaire's consistence is calculated:

$>$ Library (psych)

$>$ mcPCA <-read.table (“C://bmAgkGk2.csv", header = T, sep = “;”)

$>$ Alpha (mcPCA)

Reliability analysis

Call: $\operatorname{alpha}(x=$ mcPCA $)$

Raw alpha std. alpha G6 (smc) average $\mathrm{S} / \mathrm{N}$ ase mean sd
0.92
0.92
0.99
0.33
12
0.033 .4
0.53

Lower alpha upper $95 \%$ confidence boundaries
0.86
0.92
0.98

Acceptable values of alpha coefficient $(\alpha)$ are $\alpha>0.5$. In our example $\alpha=0.92$ which is an indicator of excellent internal consistency of questions in a questionnaire.

A questionnaire is consisted of two parts: First part (four questions) is socio-demographic characteristics and second part (24 questions) is variables that describe motivation of sales personnel in a financial institution, which is a research subject. 


\section{Identification of Principal Components}

In contemporary conditions of business running, managers have a set of theoretical and practically approved researches with regards to motivation strategy. Motivation and appropriate awarding have become key tasks and functions of human resource management and a key factor in motivation is the managers themselves. The most important task of managers in contemporary conditions of business running is to create appropriate and overall motivation system. Quality motivation system should satisfy certain types of behaviour, for example, it has to attract and retain high-quality people within business system and decrease negative influence on less capable or lower-quality employees; creativity and innovation should be supported; identification and certain level of identification of employees with organization must be insured, and their interest for its continual development and successful business running. Motivation system must insure engagement of all resources of employees in function of both personal and organizational aims realization. In a research motivation is described with the following set of variables:

(1) Salary level- $V P$;

(2) Regular salary payment $-R I$;

(3) Possibility of getting pay rise and current bonus $-D P$;

(4) Salary level is righteous by comparison with other banks $-P D$;

(5) Distribution of salaries in bank is righteous $-P R$;

(6) Working hours in bank are flexible $-F V$;

(7) Employee is able to be promoted in his/her job- $-N P$;

(8) Working atmosphere is stimulating $-R A$;

(9) Communication with colleagues and higher ranked is excellent $-K N$;

(10) Working conditions enable successfully completed work-UR;

(11) Job is interesting- $Z P$;

(12) Organization of trainings and acquiring new knowledge $-K T$;

(13) Possibility for personal development and broader education then job tasks- OR;

(14) Satisfaction with management and image of a company-UI;

(15) Possibility of influencing decision-making $-M O$;

(16) Recognition for a well done job- $D R$;

(17) Autonomy in how work is done- $-S P$;

(18) Knowledge and competences of higher ranked $-K U$;

(19) Control and feedback on successfully completed work-PI;

(20) Link between work results and award is noticeable $-R N$;

(21) Satisfaction with benefits of workplace and health care of employees- $Z Z$;

(22) Satisfaction with free time (leave, holidays, excused absence) $-Z V$;

(23) Satisfaction with services' benefits (food, place for break, parking place, mobile phones) $-Z U$;

(24) Satisfaction with all workplace's elements-OZ.

Firstly, basic socio-demographic characteristics of the respondents will be shown. In total number of respondents females dominate (83.3\%) while there are only $16.7 \%$ of males. Respondents' age is divided into four classes which are shown in Table 1.

Respondents have relatively long work experience ( $75.00 \%$ of respondents are older than 44 years of age) 
so both reliability and relevance of the questions from the questionaire can expected. The level of education of respondents has been shown in Table 2 .

Table 1

Respondents' Age

\begin{tabular}{lcc}
\hline Respondents' age (Years) & Frequency & Percent (\%) \\
\hline $20-28$ & 0 & $0.00 \%$ \\
$28-36$ & 2 & $6.25 \%$ \\
$36-44$ & 6 & $18.75 \%$ \\
44 and more & 24 & $75.00 \%$ \\
Total & 32 & $100.00 \%$ \\
\hline
\end{tabular}

Table 2

Respondents' Level of Education

\begin{tabular}{lcc}
\hline Level of education & Frequency & Percent (\%) \\
\hline Secondary school qualifications & 18 & $56.25 \%$ \\
Bachelor's degree & 8 & $25.00 \%$ \\
Graduate's degree & 6 & $18.75 \%$ \\
Total & 32 & $100.00 \%$ \\
\hline
\end{tabular}

According to level of education those who completed secondary school dominate, and after them are those who obtained bachelor's degree. The lowest number comes from those who obtained graduate's degree. Since the highest number of respondents is over 44 years of age it is logical to assume that the highest number of them is with more years of work experience. That is shown in Table 3.

Table 3

Years of Work Experience in Bank

\begin{tabular}{lcc}
\hline Years of work experience & Frequency & Percent (\%) \\
\hline Up to 5 & 2 & $6.25 \%$ \\
From 10 to 15 & 4 & $12.50 \%$ \\
From 15 to 20 & 4 & $12.50 \%$ \\
20 and more & 22 & $68.75 \%$ \\
Total & 32 & $100.00 \%$ \\
\hline
\end{tabular}

In Table 3, 68.75\% of respondents have 20 or more years of work experience in sales services within a bank. It can be assumed with certainty that their answers on 24 variables that describe motivation will be realistic and that the quality of data collected in a questionnaire is very high.

There is certain level of correlation and redundancy between the variables. The questionnaire cannot eliminate correlation among variables in advance. Therefore the components that are not in correlation will be separated (angle cosinus between those variables is zero, i.e., they reciprocally close the angle of 90\%) and separate those variable that are the most important for certain principal component using special methodological procedure of analysis.

Data with respondents' answers (see Table 4) are stored in database C://bmAgkGk2.csv ${ }^{1}$.

Data are firstly downloaded in variable mcPCA:

${ }^{1}$ Data are stored in database C://bmAgkGk2.csv on root directory of a disc. 


$$
\begin{aligned}
& >\text { mcPCA <-read.table (“C }: / / \text { bmAgkGk2.csv", header }=T \text {, sep = “;”) } \\
& >\text { mcPCA }
\end{aligned}
$$

Table 4

\begin{tabular}{|c|c|c|c|c|c|c|c|c|c|c|c|c|c|c|c|c|c|c|c|c|c|c|c|c|}
\hline & $V P$ & $R I$ & $D P$ & $P D$ & $P R$ & $F V$ & $N P$ & $R A$ & $K N$ & $U R$ & $Z P$ & $K T$ & $O R$ & $I P$ & $M O$ & $D R$ & $S P$ & $K U$ & $P I$ & $R N$ & $Z Z$ & $Z V$ & $Z U$ & $O Z$ \\
\hline 1 & 3 & 5 & 3 & 3 & 3 & 2 & 1 & 3 & 4 & 3 & 3 & 2 & 1 & 2 & 1 & 3 & 3 & 4 & 3 & 3 & 5 & 5 & 5 & 3 \\
\hline 2 & 3 & 5 & 3 & 3 & 3 & 3 & 2 & 5 & 4 & 3 & 3 & 3 & 3 & 4 & 3 & 3 & 3 & 4 & 4 & 3 & 3 & 3 & 3 & 3 \\
\hline 3 & 4 & 5 & 4 & 4 & 4 & 4 & 4 & 5 & 5 & 5 & 5 & 5 & 5 & 5 & 4 & 5 & 5 & 5 & 5 & 3 & 3 & 3 & 3 & 3 \\
\hline 4 & 3 & 3 & 2 & 2 & 1 & 2 & 2 & 3 & 3 & 3 & 2 & 3 & 2 & 2 & 1 & 1 & 3 & 3 & 1 & 5 & 4 & 4 & 5 & 4 \\
\hline 31 & 4 & 4 & 4 & 2 & 2 & 1 & 4 & 5 & 5 & 4 & 4 & 4 & 4 & 3 & 3 & 4 & 3 & 4 & 4 & 2 & 5 & 3 & 3 & 3 \\
\hline 32 & 3 & 4 & 3 & 3 & 4 & 3 & 3 & 5 & 4 & 4 & 4 & 4 & 3 & 4 & 3 & 3 & 4 & 4 & 4 & 2 & 5 & 3 & 3 & 4 \\
\hline
\end{tabular}

Respondents' Answers Data

Data are in a form of dataset where attributes (columns) are variables and rows are ordinal values of respondents' answers on questions in the questionaire. Values of answers are in form of ordinal Likert's scale with values from 1 to 5 .

Those 24 variables determine motivation of sales personnel for doing the job in a bank (job of selling serivces to clients). The researchers were interested if 24 dimensional space could be reduced at the lower number of components without losing information. An algorithm of principal components' analysis will be applied. The results of principal components' analysis are more realistic if the values of all variables are standardised. Standardised values are calculated so that arithmetic mean is decreased by variable's value and the result is divided by standard deviation. ${ }^{2}$

In $R$ language it is enough to request a function for standardisation of caGK variable and round up the result to one decimal space due to simplicity in presentation (see Table 5):

$>$ sValues $<$-round (as.data.frame (scale (mcPCA[1:24])), 1)

$>$ sValues

Table 5

\begin{tabular}{|c|c|c|c|c|c|c|c|c|c|c|c|c|c|c|c|c|c|c|c|c|c|c|}
\hline$V P \quad R I$ & $D P$ & $P D$ & $P R$ & $F V$ & $N P$ & $R A$ & $K N$ & $U R$ & $Z P$ & $K T$ & $O R$ & $I P$ & $M O$ & $D R$ & $S P$ & $K U$ & $P I$ & $R N$ & $Z Z$ & $Z V$ & $Z U$ & $O Z$ \\
\hline $\begin{array}{ll}-0.1 & 0.7\end{array}$ & -0.3 & -0.1 & -0.3 & -0.6 & -2.3 & -1.1 & -0.2 & -1.0 & -0.9 & -2.1 & -2.8 & -2.0 & -2.3 & -0.4 & -0.9 & 0.2 & -0.7 & -0.2 & 1.5 & 2.3 & 1.9 & -0.4 \\
\hline $\begin{array}{ll}-0.1 & 0.7\end{array}$ & -0.3 & -0.1 & -0.3 & 0.3 & -1.3 & 1.0 & -0.2 & -1.0 & -0.9 & -0.7 & -0.4 & 0.5 & -0.1 & -0.4 & -0.9 & 0.2 & 0.5 & -0.2 & -0.2 & 0.1 & -0.1 & -0.4 \\
\hline $\begin{array}{ll}1.2 & 0.7\end{array}$ & 0.9 & 1.3 & 0.7 & 1.2 & 0.8 & 1.0 & 1.1 & 1.5 & 1.4 & 2.1 & 2.1 & 1.7 & 1.0 & 1.3 & 2.1 & 1.3 & 1.6 & -0.2 & -0.2 & 0.1 & -0.1 & -0.4 \\
\hline $1.2-0.8$ & & -1.5 & -1.2 & -1.5 & 0.8 & 1.0 & 1.1 & 0.2 & 0.2 & 0.7 & 0.8 & -0.8 & -0.1 & 0.5 & -0.9 & 0.2 & 0.5 & -1.2 & 1.5 & 0.1 & -0.1 & -0.4 \\
\hline$-0.1-0.8$ & -0.3 & -0.1 & 0.7 & 0.3 & -0.3 & 1.0 & -0.2 & 0.2 & 0.2 & 0.7 & -0.4 & 0.5 & -0.1 & -0.4 & 0.6 & 0.2 & 0.5 & -1.2 & 1.5 & 0.1 & -0.1 & 1.1 \\
\hline
\end{tabular}

The Standardisation of Data

The standardised values of variables have the standard deviation 1 and the mean 0 , for example.:

$>$ round (sd (sValues\$VP), 2)

[1] 1

$>$ round (sd (sValues $\$ \mathrm{ZP}), 1)$

[1] 1

\footnotetext{
${ }^{2}$ Standardised values are calculate with the application of the following formula $Z_{i}=\left(Y_{i}-\bar{Y}\right) / \sigma_{y}$. Standardised values have standard deviation 1 and arithmetic mean 0.
} 
While the arithmetic mean for the level of salaries (VP) and interesting of the job (ZP) is:

$>$ Round (mean (sValues\$VP), 1)

[1] 0

$>$ Round (mean (sValues\$ZP), 1)

[1] 0

Total variance is equal to total number of variables that influence employees' motivation.

The next step in principal component analysis is calcualtion of covariance (see Table 6) using the next statement in $\mathrm{R}$ language (all the values are rounded up to two decimal points):

$>\operatorname{csV}<$-round (head (cov(sValues)) 1 )

$>\mathrm{csV}$

Table 6

Covariance Matrix of Variables

\begin{tabular}{lllllllllllllllllllllllll}
\hline & $V P$ & $R I$ & $D P$ & $P D$ & $P R$ & $F V$ & $N P$ & $R A$ & $K N$ & $U R$ & $Z P$ & $K T$ & $O R$ & $I P$ & $M O$ & $D R$ & $S P$ & $K U$ & $P I$ & $R N$ & $Z Z$ & $Z V$ & $Z U$ & $O Z$ \\
\hline$V P$ & 1.0 & 0.2 & 0.2 & -0.1 & 0.3 & 0.3 & 0.5 & 0.2 & -0.0 & -0.0 & 0.1 & 0.4 & 0.3 & 0.1 & -0.0 & 0.1 & 0.5 & 0.1 & 0.0 & -0.1 & -0.2 & -0.4 & -0.1 & -0.1 \\
$R I$ & 0.2 & 1.0 & 0.2 & 0.2 & 0.2 & 0.1 & 0.0 & 0.2 & 0.1 & 0.0 & 0.2 & 0.2 & 0.2 & 0.3 & 0.3 & 0.4 & 0.2 & 0.6 & 0.2 & -0.2 & -0.4 & -0.1 & -0.2 & -0.2 \\
$D P$ & 0.2 & 0.2 & 1.0 & 0.1 & 0.2 & 0.0 & 0.3 & 0.4 & 0.5 & 0.2 & 0.6 & 0.7 & 0.5 & 0.4 & 0.7 & 0.4 & 0.1 & 0.3 & 0.5 & 0.1 & -0.1 & -0.3 & -0.5 & -0.1 \\
$P D$ & -0.1 & 0.2 & 0.1 & 1.0 & -0.0 & -0.1 & -0.1 & -0.3 & -0.3 & 0.4 & -0.2 & -0.1 & -0.1 & 0.0 & 0.0 & -0.2 & -0.3 & -0.3 & 0.0 & -0.1 & 0.1 & 0.0 & 0.0 & 0.1 \\
$P R$ & 0.3 & 0.2 & 0.2 & -0.0 & 1.0 & 0.4 & 0.4 & 0.2 & 0.3 & 0.4 & 0.5 & 0.4 & 0.3 & 0.6 & 0.2 & 0.4 & 0.4 & -0.0 & 0.6 & -0.4 & -0.3 & -0.5 & -0.4 & -0.2 \\
$F V$ & 0.3 & 0.1 & 0.0 & -0.1 & 0.4 & 1.0 & 0.6 & 0.4 & 0.4 & 0.5 & 0.2 & 0.4 & 0.5 & 0.6 & 0.4 & 0.4 & 0.5 & 0.0 & 0.2 & -0.4 & -0.6 & -0.3 & -0.3 & -0.6 \\
\hline
\end{tabular}

In principal component analysis it is necessary to calculate the eigenvalues and corresponding eigenvectors:

$>$ eigenvalues $<$-eigen $(\operatorname{cov}(\operatorname{csV}))$

$>$ eigenvalues

$>$ round (eigenvalues $\$$ values, 2 )

[1] 1.020 .390 .250 .210 .130 .000 .000 .000 .000 .000 .000 .000 .000 .000 .000 .000 .000 .000 .00

[20] 0.000 .000 .000 .000 .00

In order to decide how many components should be retained, different methods can be used. ${ }^{3}$

By implementation plot () function, it is obvious that the change in slope occurs at the fourth component.

$>$ mcPCA.pca $<$-prcomp (sValues)

$>$ plot (mcPCA.pca, type $=$ "l")

By implementation plot () function, it is obvious that the change in slope occurs at the fourth component.

$>$ mcPCA.pca $<$-prcomp(sValues)

$>$ plot (mcPCA.pca, type $=$ "l")

As principal components those components whose characteristic values are higher than average characteristic value will be taken:

$>$ mean (round (eigenvalues\$values, 2))

3 There are different methods to select the main components:

(1) Screeplot function and mark the change in slope;

(2) Kaiser's criterion where we reatain components for which is the variance above 1 when principal component analysis was applied to standardised data;

(3) Keep the number of components required to explain at least some minimum of total variance;

(4) Take the componets with eigenvalues greater than arithmetic mean of all eigevalues. 
[1] 0.08333333

First five components have characteristic values: $1.02 ; 0.39 ; 0.25 ; 0.21 ; 0.13$; and they are higher than average value of 0.08333333 .

$>$ eigenvectors $<$-eigen (cov (standardisedValues))

$>$ round (eigenvectors, 2)

The results of previous $\mathrm{R}$ language request are showed in the following matrix (see Table 7) in which only the first five characteristic vectors have been shown:

$>$ round (eigenvectors, 2)

\section{mcPCA.pca}

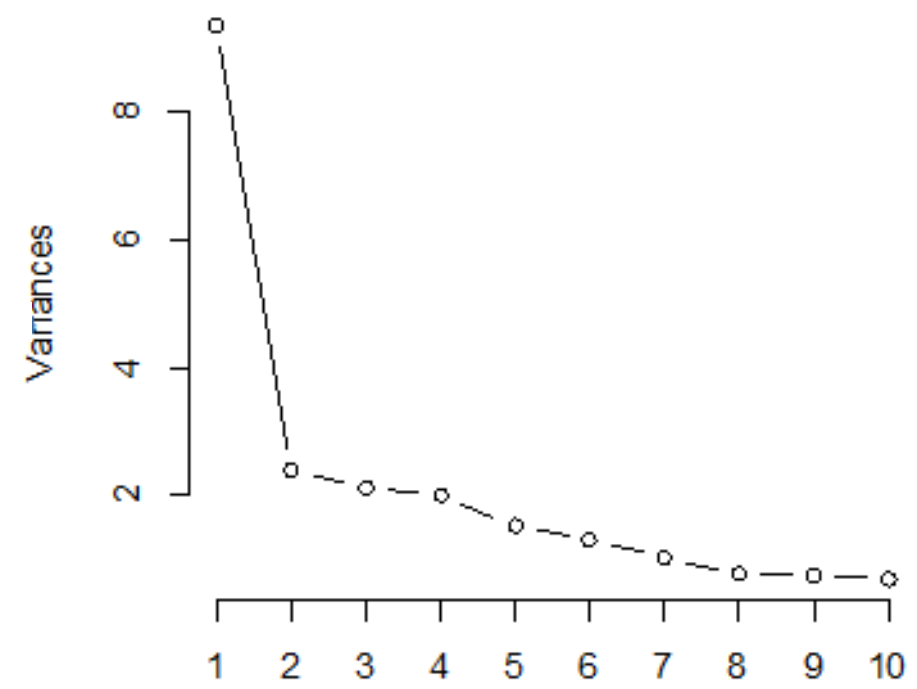

Figure 2. Screeplot function and determination the number of components

Loadings for the first five components is values of characteristic vectors (eigenvectors). ${ }^{4}$ The result is in form of matrix whose columns of loadings are for each of five principal components. The first principal component (GK1) is linear combination of variables' values:

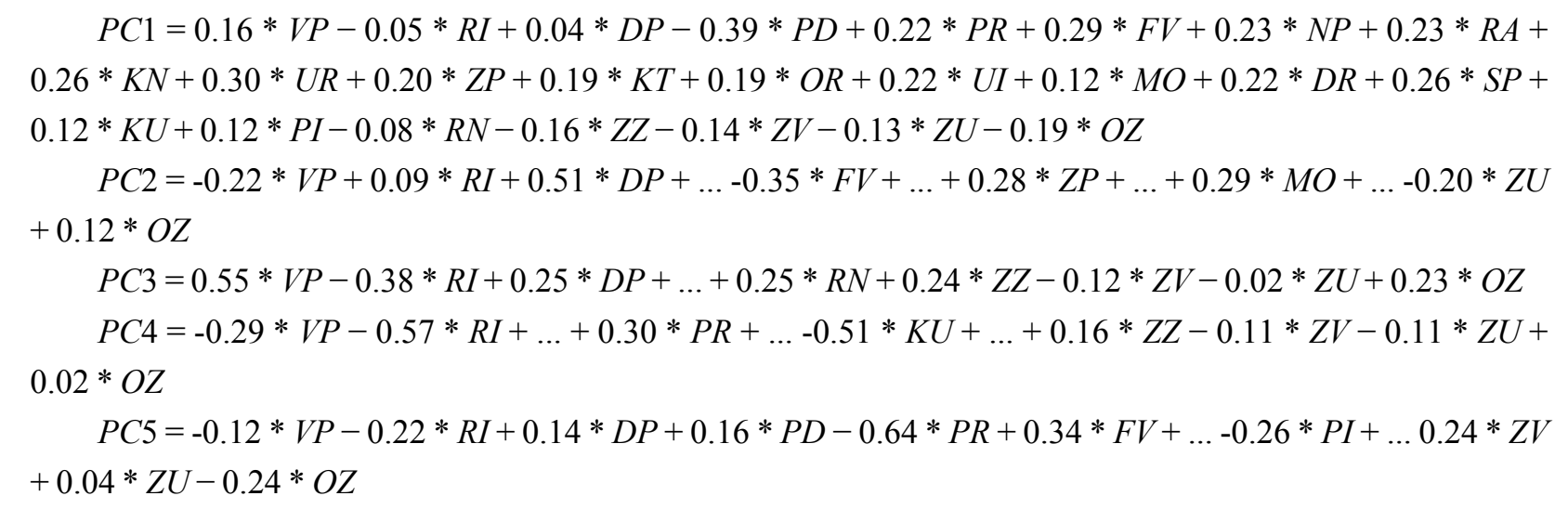

\footnotetext{
${ }^{4}$ The same result can be obtained implementing the function prcomp () on standardised dataset named sValues.
} 
Table 7

The Loadings for the First Five Characteristic Vectors

\begin{tabular}{|c|c|c|c|c|c|}
\hline & {$[P C 1]$} & {$[P C 2]$} & {$[P C 3]$} & {$[P C 4]$} & {$[P C 5]$} \\
\hline$[1]$, & 0.16 & -0.22 & 0.55 & -0.29 & -0.12 \\
\hline$[2]$, & -0.05 & 0.09 & -0.38 & -0.57 & -0.22 \\
\hline$[3]$, & 0.04 & 0.51 & 0.25 & 0.02 & 0.14 \\
\hline$[4]$, & -0.39 & 0.09 & -0.19 & 0.21 & 0.16 \\
\hline$[5]$, & 0.22 & -0.07 & -0.11 & 0.30 & -0.64 \\
\hline$[6]$, & 0.29 & -0.35 & -0.15 & 0.10 & 0.34 \\
\hline$[7]$, & 0.23 & -0.15 & 0.17 & 0.05 & 0.11 \\
\hline$[8]$, & 0.23 & 0.11 & 0.06 & -0.12 & 0.17 \\
\hline$[9]$, & 0.26 & 0.18 & -0.09 & 0.08 & 0.11 \\
\hline$[10]$, & 0.30 & -0.03 & -0.15 & 0.15 & 0.03 \\
\hline$[11]$, & 0.20 & 0.28 & 0.02 & 0.03 & -0.15 \\
\hline \multirow[t]{2}{*}[12,]{} & 0.19 & 0.18 & 0.20 & 0.03 & 0.10 \\
\hline & {$[P C 1]$} & {$[P C 2]$} & {$[P C 3]$} & {$[P C 4]$} & {$[P C 5]$} \\
\hline$[13]$, & 0.19 & 0.10 & 0.07 & 0.03 & 0.15 \\
\hline$[14]$, & 0.22 & 0.05 & -0.22 & 0.12 & 0.02 \\
\hline$[15]$, & 0.12 & 0.29 & -0.13 & 0.02 & 0.21 \\
\hline$[16]$, & 0.22 & 0.12 & -0.12 & -0.09 & -0.01 \\
\hline$[17]$, & 0.26 & -0.20 & 0.14 & -0.16 & -0.06 \\
\hline$[18]$, & 0.12 & 0.20 & -0.13 & -0.51 & -0.10 \\
\hline$[19]$, & 0.12 & 0.24 & -0.10 & 0.18 & -0.26 \\
\hline$[20]$, & -0.08 & 0.18 & 0.25 & -0.08 & 0.11 \\
\hline$[21]$, & -0.16 & 0.16 & 0.24 & 0.16 & -0.10 \\
\hline$[22]$, & -0.14 & 0.04 & -0.12 & -0.11 & 0.24 \\
\hline$[23]$, & -0.13 & 0.20 & -0.02 & -0.11 & 0.04 \\
\hline$[24]$, & -0.19 & 0.12 & 0.23 & 0.02 & -0.24 \\
\hline
\end{tabular}

The first principal component has the highest loadings (in absolute value) for $P D(-0.39$; Salary level is righteous in comparison with other banks), $F V$ (0.29; Working hours in bank are flexible), $K N(0.26$; Communication with colleagues and higher ranked is excellent), $U R$ ( 0.30 ; Working conditions enable successfully completed work). Interpretation of the first principal component might be non-material motivation. It is interesting that the analysis' results clearly indicate that righteous of salary level in comparison with other banks or comparison of salary level with other banks is an important factor of non-material stimulation of sales personnel.

The second principal component has the highest loadings (in absolute value) for $D P(0.51$; Possibility of getting pay rise and current bonus), $F V$ (-0.35; Working hours in bank are flexible), $Z P(0.28$; Job is interesting), $M O(0.29$; Possibility of influencing decision-making). Interpretation of the second principal component is combination of material and non-material stimulation that enables both flexible working hours and influencing decision-making.

The third principal component has the highest loadings for $V P$ (0.55; Salary level), $R I$ (-0.38; Regular salary payment). The third component reflects the level and regular salary payment. It is material stimulation of employees.

The fourth component has the highest loadings for $V P(-0.29$; Salary level), $R I$ ( -0.57 ; Regular salary payment), $P R$ (0.30; Distribution of salaries in bank is righteous), and $K U(-0.51 ; P R$-Knowledge and 
competences of higher ranked). That component reflects distribution.

The fifth component has loadings for $P R$ (-0.64; Distribution of salaries in bank is righteous), $F V(0.34$; Working hours in bank are flexible), and $P I$ ( -0.26 ; Control and feedback on successfully completed work). That component reflects organisational elements of control and managing manner (righteous of distribution and feedback about quality of doing the job).

The research results show that all 24 variables, which are motivational nature and reflect the overall employees motivation in conducting sales in banks (the most important financial institutions), can be described with five components: non-material motivation, combination of material and non-material stimulation, righteous of distribution, and managing manner. It can be concluded that non-material forms dominate in total motivation system.

\section{Conclusions}

The research has confirmed the hypothesis that numerous different forms of motivation, which simultaneously influence on doing the job of sales in financial institutions, can be reduced to lower number of components. Dataset was created based on data obtained from respondents' answers in the questionnaire. It consists of answers on questions in form of Likert's scale. Conclusions are drawn as follows:

(1) The algorithm of principal components' analysis was applied on data and it reduced 24 dimensional spaces on five components.

(2) Five dimensional space, which is simpler one, shows that motivation system must be based on satisfying needs that are not only of material but also of social and psychological (which reflected in needs of individual's growth and development, recognition of capabilities, status, cooperation and social contacts, security) nature.

(3) The motivation system based on material elements (salary level) must be completed with stimulations that satisfy those needs besides existential and material ones.

(4) The practice of motivation, besides the salaries as the most significant form of material stimulation, must enable righteous distribution, control of doing the job quality, flexible working hours, and working environment that enables excellent communication with higher ranked.

(5) The salaries, righteous distribution, control of doing the job quality, flexible working hours, and working environment are the most significant components in motivation system of sales personnel within the financial institutions.

\section{References}

Anić, S., Klaić, N., \& Domović, M. (1999). Rječnik stranih riječi. Zagreb: Sani-Plus.

Batijarević-Šiber, F. (1999). Menagament ljudskih potencijala. Zagreb, Golden marketing.

Bijakšić, S., Markić, B., \& Bevanda, A. (2013). Text mininig i analiza stavova i mišljenja na društvenim mrežama. Proceedings of the International Conference: Tourism Today for Tomorrow, Šibenik, p.411-417.

Buble, M. (2006). Osnove menadžmenta. Zagreb: Sinergija.

Markić, B. (2011). Integrating the ory and practice: Knowledge discovery and unsupervised learning. Meeting of Management Departments the Faculties of Economics, Split, Faculty of Economics University of Split. 